\title{
Reevaluating the Classification of Paracoccus halodenitrificans with Sequence Comparisons of 16S Ribosomal DNA
}

\author{
J. M. MILLER, ${ }^{*}$ S. J. DOBSON, P. D. FRANZMANN, AND T. A. MCMEEKIN \\ Australian Collection of Antarctic Microorganisms, Antarctic-CRC, and Department of \\ Agricultural Science, University of Tasmania, Hobart 7001, Australia
}

\begin{abstract}
The results of phylogenetic analysis in which $16 \mathrm{~S}$ ribosomal DNA sequences were compared confirmed previous chemotaxonomic data which suggested that Paracoccus halodentrificans is inappropriately placed in the genus Paracoccus, which belongs in the $\alpha$ subclass of the Proteobacteria. P. halodenitrificans should be placed in the family Halomonadaceae, which belongs in the $\gamma$ subclass of the Proteobacteria.
\end{abstract}

A phylogenetic relationship between Paracoccus denitrificans and Paracoccus halodenitrificans has never been established. The $\mathrm{G}+\mathrm{C}$ contents of these two species are comparable (64 to $67 \mathrm{~mol} \%$ ) and are consistent with the physiological similarities that prompted the initial congeneric classification of the organisms (11). rRNA catalog and sequence data for the type species of the genus Paracoccus, $P$. denitrificans, place this organism in the $\alpha$ subclass of the Proteobacteria $(4,8-10)$, but no phylogenetic data for $P$. halodenitrificans are available.

The results of a quinone and fatty acid analysis of members of the genus Paracoccus strongly suggested that the species $P$. halodenitrificans should be excluded from the genus (14). The major respiratory quinone of $P$. denitrificans is ubiquinone 10 , and its principal cellular fatty acids are 18:0,10:0, and 14:0.P. halodenitrificans, however, has the same lipid profile as members of the genus Halomonas in the $\gamma$ subclass of the Proteobacteria (5), which have ubiquinone 9 as their major respiratory quinone and contain 18:1, 16:0,16:1, cy19:0, and cy17:0 as their principal fatty acids. Furthermore, the range of $\mathrm{G}+\mathrm{C}$ contents of the halomonads (52 to $68 \mathrm{~mol} \%$ [6]) accommodates the $\mathrm{G}+\mathrm{C}$ content of $P$. halodenitrificans ( 64 to $66 \mathrm{~mol} \%$ ).

To clarify the taxonomic status of $P$. halodenitrificans, we compared the sequence of its 16S rRNA gene with the sequence of the $P$. denitrificans (8) $16 \mathrm{~S}$ rRNA gene and with the $16 \mathrm{~S}$ rRNA gene sequences of members of the family Halomonadaceae.

The type strain of $P$. halodenitrificans, strain ATCC 13511 (= DSM 735), was cultured in nutrient broth (Difco) supplemented with $6 \% \mathrm{NaCl}$. DNA was extracted from the cells, and the $16 \mathrm{~S}$ rRNA gene was amplified by PCR and sequenced as previously described (2).

The 16S rRNA sequence of $P$. halodenitrificans was aligned with previously described $16 \mathrm{~S}$ rRNA sequences of species belonging to the Halomonadaceae. The PHYLIP package (version 3.4) was used to establish phylogenetic relationships between species, and Jukes-Cantor distances were calculated with the DNADIST program. A phylogenetic tree was derived with the FITCH program, with a randomized order of input sequences and global rearrangement (3). The species Escherichia coli, Pseudomonas aeruginosa, and Oceanospirillum linum, which are also members of the $\gamma$ subgroup of the Proteobacteria, were used as reference organisms in the analysis. Our results placed $P$. halodenitrificans in the family

\footnotetext{
* Corresponding author. Mailing address: Department of Agricultural Sciences, University of Tasmania, GPO Box 252C, Hobart, Tasmania, Australia 7001. Phone: 6102 202276. Fax: 6102202642. Electronic mail address: Janine.Miller@agsci.utas.edu.au.
}

Halomonadaceae (Fig. 1). The percentages of similarity between $P$. halodenitrificans and the other species examined are shown in Table 1.

The 16S rRNA sequence of $P$. halodenitrificans was examined for the 17 signatures which define the Halomonadaceae (2). All of these signatures occur in the $P$. halodenitrificans sequence, including the cytosine at position 486 that distinguishes members of the family Halomonadaceae (2).

We therefore propose that $P$. halodenitrificans should be transferred to the family Halomonadaceae in the $\gamma$ subclass of the Proteobacteria. It is not possible at this time to place $P$.

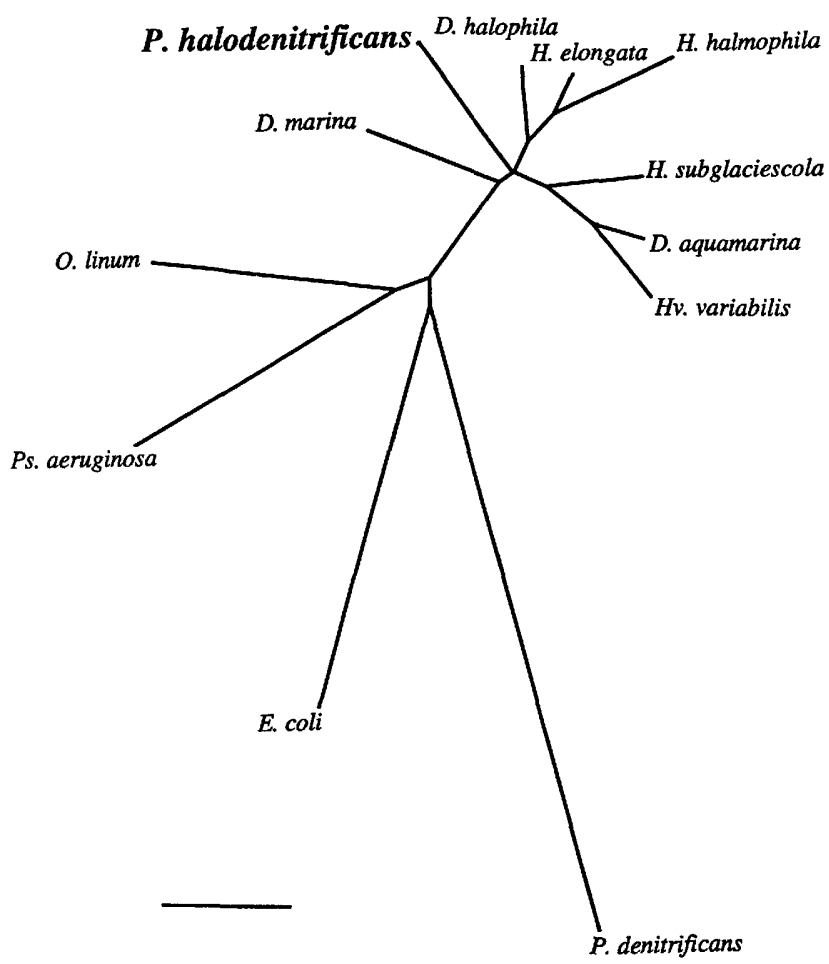

FIG. 1. Phylogenetic tree derived by performing a distance analysis of $16 \mathrm{~S}$ rRNA sequences, showing the relationships among $P$. denitrificans, $P$. halodenitrificans, members of the family Halomonadaceae, and other members of the $\gamma$ subclass of the Proteobacteria. (All sequences were obtained from the Ribosomal Database unless indicated otherwise in the text.) Bar $=0.03$ evolutionary distance unit as calculated by the Jukes-Cantor method. Abbreviations: H., Halomonas; D., Deleya; Hv., Halovibrio; P., Paracoccus; E., Escherichia; Ps., Pseudomonas; $O$., Oceanospirillum. 
TABLE 1. Levels of $16 \mathrm{~S}$ rRNA similarity between $P$. halodenitrificans and some other members of the Proteobacteria ${ }^{a}$

\begin{tabular}{|c|c|}
\hline Species & $\%$ Similarity \\
\hline Deleya halophila.. & 94.3 \\
\hline 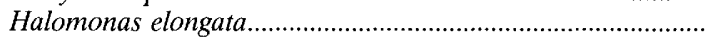 & 93.8 \\
\hline Deleya aquamarina & 93.8 \\
\hline Halomonas subglaciescola ......... & 93.7 \\
\hline 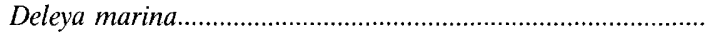 & 93.5 \\
\hline Halomonas halmophila & 92.3 \\
\hline  & 91.7 \\
\hline 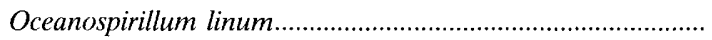 & 88.3 \\
\hline Pseudomonas aeruginosa & 86.3 \\
\hline Escherichia coli.................................. & 84.6 \\
\hline 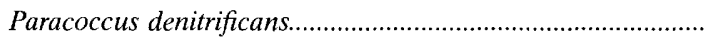 & 79.9 \\
\hline
\end{tabular}

${ }^{a}$ Values were calculated from pairwise mean distance values derived PAUP, version 3.0 (13). For more extensive distance data for members of the Halomonadaceae see reference 2 .

halodenitrificans in one of the three genera of this family. The genera Deleya, Halomonas, and Halovibrio have been shown to be indistinguishable by phenotypic, chemotaxonomic, and molecular criteria $(1,2,5,7,12)$. Until the internal structure of the family Halomonadaceae is clarified at the genus level, assigning $P$. halodenitrificans to a genus would be arbitrary and artificial.

Nucleotide sequence accession numbers. The sequence of the 16S rRNA gene of $P$. halodenitrificans ATCC $13511^{\mathrm{T}}$ has been deposited in the GenBank data base under accession number L04942.

We thank Kevin Sanderson for assistance with part of the study.

This work was funded by the Australian Research Council. P.D.F. and S.J.D. were supported by Australian Research Council fellowships.

\section{REFERENCES}

1. Dobson, S. J. 1988. BSc. (Hons.) thesis. University of Tasmania, Hobart, Tasmania, Australia.

2. Dobson, S. J., T. A. McMeekin, and P. D. Franzmann. 1993. Phylogenetic relationships between some members of the genera
Deleya, Halomonas, and Halovibrio. Int. J. Syst. Bacteriol. 43:665673.

3. Felsenstein, J. 1989. PHYLIP—phylogeny inference package (version 3.2). Cladistics 5:164-166.

4. Fox, G. E., E. Stackebrandt, R. B. Hespell, J. Gibson, J. Manilof, T. A. Dyer, R. S. Wolfe, W. E. Balch, R. S. Tanner, L. J. Magrum, L. B. Zablen, R. Blakemore, R. Gupta, L. Bonen, B. J. Lewis, D. A. Stahl, K. R. Luehrsen, K. N. Chen, and C. R. Woese. 1980. The phylogeny of prokaryotes. Science 209:457-463.

5. Franzmann, P. D., and B. J. Tindall. 1990. A chemotaxonomic study of members of the family Halomonadaceae. Syst. Appl. Microbiol. 13:142-147.

6. Franzmann, P. D., U. Wehmeyer, and E. Stackebrandt. 1988. Halomonadaceae fam. nov., a new family of the class Proteobacteria to accommodate the genera Halomonas and Deleya. Syst. Appl. Microbiol. 11:16-19.

7. James, S. R., S. J. Dobson, P. D. Franzmann, and T. A. McMeekin. 1990. Halomonas meridiana, a new species of extremely halotolerant bacteria isolated from Antarctic saline lakes. Syst. Appl. Microbiol. 13:270-278.

8. Ludwig, W., G. Mittenhuber, and C. G. Friedrich. 1993. Transfer of Thiosphaera pantotropha to Paracoccus denitrificans. Int. J. Syst. Bacteriol. 43:363-367.

9. MacKay, R. M., D. Salgado, L. Bonen, E. Stackebrandt, and W. F. Doolittle. 1982. The 5S ribosomal RNAs of Paracoccus denitrificans and Prochloron. Nucleic Acids Res. 10:2963-2970.

10. MacKay, R. M., L. B. Zablen, C. R. Woese, and W. F. Doolittle. 1979. Homologies in processing and sequence between the $23 \mathrm{~S}$ ribosomal ribonucleic acids of Paracoccus denitrificans and Rhododpseudomonas sphaeroides. Arch. Microbiol. 123:165-172.

11. Robinson, J., and N. E. Gibbons. 1952. The effects of salts on the growth of Micrococcus halodenitrificans n. sp. Can. J. Bot. 30:147154.

12. Skerratt, J. H., P. D. Nichols, C. A. Mancuso, S. R. James, S. J. Dobson, T. A. McMeekin, and H. Burton. 1991. The phospholipid ester-linked fatty acid composition of members of the family Halomonadaceae and genus Flavobacterium. A chemotaxonomic guide. Syst. Appl. Microbiol. 14:8-13.

13. Swofford, D. L. 1990. PAUP: phylogenetic analysis using parsimony, version 3.0. Illinois Natural History Survey, Champaign.

14. Urakami, T., H. Araki, H. Oyanagi, K.-I. Suzuki, and K. Komagata. 1990. Paracoccus aminophilus sp. nov. and Paracoccus aminovorans sp. nov., which utilize $N, N$-dimethylformamide. Int. J. Syst. Bacteriol. 40:287-291. 